\title{
The Impact of Federal Crop Insurance on the Conservation Reserve Program
}

\section{Nathan DeLay}

I directly estimate the acre-for-acre impact of crop insurance participation on Conservation Reserve Program (CRP) enrollment at the county level. The government may be sponsoring competing interests if subsidized insurance expands production at the expense of CRP. I employ an instrumental variables technique to correct for endogeneity in insurance decisions. Results suggest that an additional 1,000 acres insured reduces CRP enrollment by about three acres, though effect sizes vary by region. Local policy initiatives such as conservation compliance incentives could help offset local environmental consequences of converting land from CRP to insured production.

Key Words: conservation reserve program, Federal crop insurance, land retirement, subsidies

\section{Introduction}

Farm policy in the United States has increasingly emphasized crop insurance as the main risk-management option for farmers. To this end, the Federal Crop Insurance Corporation (FCIC) subsidizes crop insurance premiums so farmers do not bear the full cost of insurance. Program participation has increased rapidly in recent decades. The percentage of crop acres insured under the program grew from 36 percent in 1990 to 73 percent in 2000 and has since risen above 80 percent of all cropland. Program costs have also grown substantially. In 2012, the federal government spent over $\$ 14$ billion on the crop insurance program, up from \$1.4 billion in 1995 (USDA RMA 2016).

The Conservation Reserve Program (CRP) is America's largest voluntary conservation program. CRP pays farmers to remove environmentally sensitive cropland from production and plant resource-conserving covers such as grasses and trees. As of 2017, 23.4 million acres were enrolled in the program nationwide, costing the government $\$ 1.8$ billion (USDA FSA 2018). CRP has been touted for producing environmental and wildlife benefits that more than offset its cost to taxpayers (Wu and Weber 2012). Wildlife and recreation amenities conferred by conserving cropland generate positive spillover effects. Gleason et al. (2008) estimate that CRP helped restore 5.4 million acres of migratory bird habitat in the Prairie Pothole Region of the Northern Great Plains.

Nathan DeLay, Purdue University, Agricultural Economics, West Lafayette, Indiana Correspondence: Nathan DeLay, Purdue University, Agricultural Economics, West Lafayette, Indiana, Email: ndelay@purdue.edu

Agricultural and Resource Economics Review 48/2 (August 2019) 297-327

(C) The Author(s) 2019. This is an Open Access article, distributed under the terms of the Creative Commons Attribution licence (http://creativecommons.org/licenses/by/4.0/), which permits unrestricted re-use, distribution, and reproduction in any medium, provided the original work is 
The purpose of this paper is to examine the acreage effects of crop insurance on CRP. Crop insurance subsidies may affect CRP participation by altering the expected returns associated with marginal cropland. Crop insurance subsidies lower the out-of-pocket expense of insurance relative to potential losses, making environmentally sensitive cropland more attractive for planting insurable crops. The government may be effectively competing with itself over sensitive cropland by sponsoring conflicting interests.

I hypothesize that additional acreage insured under federal crop insurance draws down the amount of land enrolled in CRP. Displacement can be at most one-for-one (i.e., an acre taken out of CRP cannot increase production by more than one acre). Therefore, I predict the crowding-out effect to be between zero and one and small. The effect is also likely to vary geographically. In homogenous parts of the country where land eligible for CRP is plentiful and the margin between production and retirement is thin, such as the Upper Midwest and the Corn Belt, crowding out will be more pronounced. In areas where CPR-eligible land is scarce and crop production competes with many land use practices, such as haying or livestock grazing, the effect will be less detectable or nonexistent.

Land on the extensive margin of production can be more erodible and prone to nutrient runoff, and it may require greater application of chemical fertilizers. Hence, government policies that reduce the economic vulnerability of land could encourage negative environmental outcomes (Lubowski et al. 2006). In their seminal paper, Goodwin, Vandeveer, and Deal (2004) show small but statistically significant increases in acreage planted to insured crops. Young, Vandeveer, and Schnepf (2001) find similarly small acreage effects. They simulate the complete elimination of all crop-insurance subsidies, finding that total acres in production would shrink by a mere 0.4 percent.

Though small, acreage effects may imply larger environmental damage if occurring at the extensive margin. Areas likely to shift into production due to crop insurance are more susceptible to environmental damage (Wu and Adams 2001). Wu (1999) demonstrates that crop insurance encourages the conversion of land from low-impact pasture and hay to chemically intensive corn production. Environmental effects also vary regionally. As many as 157,900 acres of grassland in the Prairie Pothole Region were converted to crop production as a direct result of crop-insurance subsidies, according to Miao, Hennessy, and Feng (2016), while Walters et al. (2012) show both negative and positive environmental effects attributable to crop insurance, depending on geography.

Several papers examine the factors that influence CRP enrollment and reenrollment. High commodity prices are found to draw acreage out of CRP (Secchi et al. 2009; Rashford, Walker, and Bastian 2010; Stubbs 2014; Wachenheim, Lesch, and Dhingra 2014), while Ifft, Rajagopal, and Weldzuis (2018) find that proximity to ethanol production facilities actually increased CRP re-enrollment rates in the Upper Great Plains and Corn Belt. Participants also have non-financial motives, including preferences for wildlife habitat and 
environmental amenities (Lambert et al. 2006). Hendricks and Er (2018) point out the importance of government policy in shaping CRP enrollment over time. They show that program administrators exert influence by adjusting the national enrollment cap and setting maximum acceptable bids for land offered through the General Sign-up convention. These mechanisms are at least partly informed by supply management concerns (e.g., the enrollment cap typically falls [rises] following periods of high [low] commodity prices).

The influence of subsidized crop insurance on the CRP has important policy implications but has not been addressed extensively in the literature. Miao et al. (2016) show that, because it ignores savings from avoided crop insurance subsidies, the current CRP enrollment mechanism is inefficient. Miao et al. (2016) propose an alternative mechanism that both increases enrollment in CRP and generates environmental benefits without altering total government outlays.

Lubowski et al. (2006) simulate what would have happened to various types of land had subsidy increases brought about by the Federal Crop Insurance Reform Act of 1994 (FCIRA) not occurred. They estimate that the FCIRA reduced acreage in CRP by only 0.11 percent. Claassen, Langpap, and $\mathrm{Wu}$ (2017) examine how federal crop insurance influences land use and cropping patterns in the Corn Belt states. Using parcel-level data, they simulate the introduction of revenue crop insurance, showing a decline of 0.23 percent in CRP acreage. Feng, Hennessy, and Miao (2013) find that increasing crop insurance subsidies by one dollar per acre would reduce the amount of land offered for CRP enrollment by about 6,000 acres in the Dakotas.

The aforementioned studies generally show that crop insurance has a small effect on the conversion of land out of CRP and into crop production. Any environmental consequences that follow are found to be small or negligible. Both Lubowski et al. (2006) and Claassen, Langpap, and Wu (2017), however, rely on simulations and do not make the acreage effects of insurance on CRP the focus of their analysis, while Feng, Hennessy, and Miao (2013) examine a single geographic region.

I extend the work of Miao et al. (2016), Lubowski et al. (2006), Claassen, Langpap, and $\mathrm{Wu}$ (2017), and Feng, Hennessy, and Miao (2013) on the extensive margin by directly estimating the acre-for-acre impact of subsidized crop insurance on CRP enrollment over an extensive period. I examine the relationship between insurance and CRP regionally, giving results greater external validity. Previous studies either consider the national level or specific sub-regional geographic areas. Using a comprehensive dataset spanning 25 years, I estimate the change in CRP acreage resulting from an additional acre insured under federal crop insurance.

Results indicate that crop insurance crowds out a small but statistically significant amount of CRP land (an average of three acres removed for every 1,000 additional acres insured) and that effect sizes vary by region. Regions with both high row-crop production and CRP participation such as the Corn Belt, Great Lakes, and Northern Plains are the most susceptible to crowd out, 
while I detect little or no crowd out in other parts of the country. Two forces may be driving regional differences: variation in the amount and type of land eligible for CRP and land use heterogeneity. Because the analysis is performed at the county level, aggregating individual farms with positive CRP enrollment together with ineligible farms may introduce an aggregation bias that underreports the true effect. Regions with high CRP eligibility, such as the Corn Belt, will be less affected by this type of bias than regions where CRP-eligible land is sparse (e.g., states in the Southwest). Secondly, the effect of crop insurance on CRP depends on the number of alternative land uses for crop production to displace. Though small, the effects detected in this paper are consistent with the existing literature.

In the following section, I present a theoretical framework to model the tradeoff between crop production and land retirement. From there I describe the data used for this analysis and discuss the empirical strategy, results, and potential policy implications.

\section{Theoretical Model of Crop Insurance and CRP Trade-Off}

A representative producer faces a trade-off between production and participation in CRP. The relative costs and benefits of each option determine how much of the producer's total land holdings he or she devotes to each. The availability of government subsidized crop insurance may change the size of these relative benefits in favor of production over conservation.

I model the behavior of the representative producer following Chang and Boisvert (2009), who offer a household production model approach. ${ }^{1}$ The producer allocates his or her total endowment of land, $\bar{A}$, between crop production, $A_{p}$, and CRP enrollment, $A_{c}$. Though the entire endowment of land may be planted to crops, soil productivity varies within the field. A portion of land, $A_{m}(q)$, is considered marginal cropland characterized by poor soil productivity (e.g., highly erodible land [HEL]). The amount of marginal cropland is exogenously determined by $q$, the soil characteristics of the farm which vary across geographic regions. The amount of marginal cropland eligible for enrollment into CRP is $\bar{A}_{c} \equiv t \cdot A_{m}(q)$, where $t \in[0,1]$ reflects national and regional acreage caps set by government policy. ${ }^{2}$ Limits on enrollment vary over time (national cap) and across regions (county cap). ${ }^{3}$

\footnotetext{
1 Though I ultimately use aggregated county-level data in estimation, it is useful to understand land-use trade-offs at the producer level.

2 Under the General sign-up convention, acres offered for enrollment are ranked according to their Environmental Benefits Index (EBI) score. Policy makers establish a minimum acceptable EBI to meet the national enrollment cap. Acceptance rates vary between 22 and 70 percent in any given year (Hendricks and Er 2018). The proportion of marginal land eligible for enrollment, , can also be thought of as the probability of acceptance.

3 The national CRP enrollment cap establishes the maximum number of acres that may be enrolled in the program at any given time. The national cap is typically set by the Farm Bill to
} 
Given there are only two land use choices, the amount of marginal cropland in production is defined as $A_{p}^{m} \equiv A_{m}(q)-A_{c}$, the difference between marginal land and the portion of marginal land enrolled in CRP.

I employ a Just and Pope (1979) production function where output (yield per acre harvested) is a function of both a deterministic component and a stochastic shock.

$$
y\left(A_{p}^{m}, \varepsilon ; q\right)=f\left(\Gamma\left(q, A_{p}^{m}\right)\right)+\Gamma\left(q, A_{p}^{m}\right)^{-1} \cdot \varepsilon
$$

The deterministic component, $f(\cdot)$, depends on the average soil quality of land in production, represented by the term $\Gamma(\cdot){ }^{4}$ Average soil quality itself depends on two factors: an exogenous soil quality index $q$, which varies regionally and across farms, and $A_{p}^{m}$, the amount of marginal cropland placed in production. The former captures regional heterogeneity in cropping capability, where $\Gamma_{q}>0$. For example, a well-drained farm in Iowa will be endowed with a higher $q$ than a typical farm in the arid West. The latter incorporates the effect of intra-field land allocation choices on crop yields. The average quality of soil in production will fall as additional marginal acres are brought into production ("fence to fence" planting), making the partial $\Gamma_{A_{p}^{m}}$ negative.

The stochastic portion of yield is captured by the terme, which represents negative production shocks such as drought, hail, or flooding. Yield risk is assumed to be i.i.d. distributed, where $\varepsilon \leq 0, \mathbb{E}(\varepsilon)=\bar{\varepsilon}<0$, and $\operatorname{VAR}(\varepsilon)=\sigma_{\varepsilon}^{2}$. Production shocks are mitigated by the average soil quality of planted land. Higher values of $\Gamma(\cdot)$, due either to superior regional soil characteristics or a smaller amount of marginal land in production, attenuates the negative effect of $\varepsilon$ on yields toward zero. ${ }^{5}$ The output price per unit of yield, $p$, is assumed to be exogenous to the producer and independent of land-use decisions.

The farmer purchases federal crop insurance on planted acres, which triggers an indemnity payment, $I\left(\varepsilon, \Gamma\left(q, A_{p}^{m}\right)\right)$, per acre in the event of a loss caused by the random shock, $\varepsilon$. Higher values of $\varepsilon$ and lower values of $\Gamma(\cdot)$ raise the frequency and size of insurance indemnities. The total premium cost per acre, $\nu(\bar{\varepsilon}, q)$, is made to be actuarially fair for a given region based on expected losses, $\bar{\varepsilon}$, and regional soil characteristics. ${ }^{6}$ The government subsidizes

\footnotetext{
meet budget and overall program goals. Enrollment at the county level is capped at 25 percent of total cropland acres.

4 The deterministic portion of the Just and Pope (1979) production function is typically modeled using producer inputs or farm practice. I modify the model to include a soil quality component.

5 The stated functional form allows for both the expected value and variability of output to be improved by higher soil quality, i.e., $\mathrm{dE}(\mathrm{y}) / \mathrm{d} \Gamma>0$ and $\mathrm{dVAR}(\mathrm{y}) / \mathrm{d} \Gamma<0$ (Just and Pope, 1979).

6 Actuarially fair premiums are set equal to expected indemnities for a region, i.e., $v(\bar{\varepsilon}, q)=I(\bar{\varepsilon}, q)$. The USDA Risk Management Agency (RMA) sets actuarially fair premiums by county, crop, farm practice, policy type, and unit structure.
} 
premiums at rate $s \in(0,1)$, so the per-acre insurance cost to the producer is $(1-s) \cdot v(\bar{\varepsilon}, q)$.

The producer receives an annual rental payment, $r(q, t)$, for each acre enrolled in CRP. Rental rates are determined by the USDA Farm Service Agency (FSA) according to the soil properties of the region and prevailing cropland rent but are also influenced by government policy which sets maximum rates participants may receive during a given period. ${ }^{7}$

The producer allocates land to maximize expected utility from farm profits, $\pi$ $\left(A_{p}, A_{c}\right)$, and environmental amenities generated by land enrolled in CRP, $e\left(A_{c}\right)$. Environmental amenities include recreation and wildlife viewing and capture the non-monetary motivations for enrolling in the program. The importance of environmental amenities in the producer's utility likely vary according to demographics and farm type (Lambert et al. 2006).

The producer's constrained optimization problem is as follows:

$$
\max _{A_{p}, A_{c}} \mathbb{E}\left\{\mathbb{U}\left[\pi\left(A_{p}, A_{c}\right), e\left(A_{c}\right)\right]\right\}
$$

subject to:

$\pi\left(A_{p}, A_{c}\right)=\left\{p \cdot\left[f\left(\Gamma\left(q, A_{p}^{m}\right)\right)+\Gamma\left(q, A_{p}^{m}\right)^{-1} \cdot \varepsilon\right]+I\left(\varepsilon, \Gamma\left(q, A_{p}^{m}\right)\right)-(1-s) \cdot v(\bar{\varepsilon}, q)\right\}$
$\cdot A_{p}+r(q, t) \cdot A_{c}$

$$
\begin{gathered}
A_{p}+A_{c}=\bar{A} \\
A_{c} \leq \bar{A}_{c}=t \cdot A_{m}(q) \\
A_{p}, A_{c} \geq 0
\end{gathered}
$$

Constraint equation 4 assumes the producer can only allocate land between crop production and retirement. This is most representative of regions such as the Corn Belt, where soil productivity restricts the number of competing land uses, but is less representative of areas such as the West and Southern Plains, where crop production must compete with grassland pasture and forest (Bigelow and Borchers 2017). Constraint equation 5 defines the CRP eligibility limit as a function of the amount of marginal land, determined by regional soil characteristics, and government policy. Note that equation 5 may not be binding. In such a case, part or all the land eligible for CRP is put into

\footnotetext{
7 In practice, the producer can affect the rental rate through the General sign-up competitive bidding process. By offering to accept less than the established rate, the producer raises the probability of being accepted into CRP. For tractability, I assume the producer receives the maximum allowable rental rate set for his or her region.
} 
production. Non-negativity constraints for the choice variables are stated in equation 6.

Substituting equation 4 into the objective function and using the definition of marginal cropland makes the constrained optimization problem a function of only $A_{c}{ }^{8}$

$$
\begin{gathered}
L\left(A_{c}, \lambda\right)= \\
E\left\{\mathbb { U } \left[\left[p\left[f\left(\Gamma\left(q, A_{p}^{m}\right)\right)+\Gamma\left(q, A_{p}^{m}\right)^{-1} \varepsilon\right]+\mathrm{I}\left(\varepsilon, \Gamma\left(q, A_{p}^{m}\right)\right)\right.\right.\right. \\
\left.\left.-(1-s) v(\bar{\varepsilon}, q)]\left(\bar{A}-A_{c}\right)+r(q, t) A_{c}, e\left(A_{c}\right)\right]\right\}-\lambda\left(A_{c}-t A_{m}(q)\right) \#
\end{gathered}
$$

Kuhn Tucker conditions defining an optimum are as follows:

$$
\begin{aligned}
& E\left\{\mathbb { U } _ { \pi } \cdot \left[\left(\bar{A}-A_{c}\right)\left[p\left(-f^{\prime}(\cdot) \Gamma_{A_{p}^{m}}+\Gamma(\cdot)^{-2} \Gamma_{A_{p}^{m}} \varepsilon\right)-\mathrm{I}_{\Gamma} \Gamma_{A_{p}^{m}}\right]-p\left[f(\cdot)+\Gamma(\cdot)^{-1} \varepsilon\right]\right.\right. \\
& \quad-\mathrm{I}(\cdot)+(1-s) v(\cdot)]+E\left(\mathbb{U}_{\pi} \cdot r(\cdot)\right)+E\left(\mathbb{U}_{e} \cdot e^{\prime}(\cdot)\right)-\lambda=0 \#
\end{aligned}
$$

$$
\begin{gathered}
A_{c}-t A_{m}(q) \leq 0 \\
\lambda\left(A_{c}-t A_{m}(q)\right)=0 \\
\lambda \geq 0
\end{gathered}
$$

where $\mathbb{U}_{\pi}$ and $\mathbb{U}_{e}$ represent marginal utility from farm profit and environmental amenities, respectively. Equation 8 shows that the optimal land allocation equates the expected marginal utility of crop production profit with the expected marginal utility of CRP revenue plus the marginal utility of environmental amenities generated by land in CRP minus $\lambda$, the shadow price of CRP eligibility. The shadow price represents the marginal utility of increasing the amount of land eligible for CRP, either by changing the endowment of marginal cropland or by raising the number of acres the government allows to enter the program. If the producer derives a large amount of utility from CRP's environmental benefits and would like to enroll more than is allowed by the cap (i.e., if constraint equation 5 is binding, a higher enrollment cap would cause him or her to put more land in CRP and increase their optimal utility). Lambda is then positive if $A_{c}=t A_{m}(q)$ and zero if $A_{c}<t A_{m}(q)$.

\footnotetext{
8 Note that the definition of marginal cropland as a function of conserved land, $A_{p}^{m}=A_{m}(q)-A_{c}$, is suppressed in equation 7 for simplicity.
} 
The optimal choice of $A_{c}$ is found by simultaneously satisfying equations 8-11, which I express in reduced form as a function of exogenous variables.

$$
A_{c}^{*}=A_{c}^{*}(p, \varepsilon, s, q, t, \lambda)
$$

The relationship of interest is the effect of decreasing the out-of-pocket cost of insurance, which increases the returns to production (including on marginal cropland) on the amount of acreage retired into CRP. Provided actuarially fair premiums remain constant, the per-acre cost of insurance to the producer will fall due to an increase in the government-determined subsidy rates. The sign and size of the relationship between subsidy rates and CRP are a function of the exogenous covariates of the model: output price, weather shocks, regional soil characteristics, and the enrollment cap.

Importantly, the relationship at the farm level depends on the degree to which land can come in and out of the program (i.e., how limited CRP enrollment is by constraint equation 5). If regional soil properties, $q$, and the government enrollment cap, $t$, are such that little or no land is eligible for CRP to begin with, any change in insurance subsidies (or any other variable) will have little or no impact on CRP enrollment. Conversely, if $t A_{m}(q)$ is positive but constraint equation 5 is binding, then all eligible land that can be enrolled in CRP is enrolled. The amount of land the producer would like to enroll may greatly exceed eligibility. CRP will again be unresponsive to changes in crop insurance. This example reflects a farm in a county at or near its CRP acreage cap.

The effect of insurance subsidization on CRP is best observed in farms where $\bar{A}_{c}(q)>0$ and $0<A_{c}<t A_{m}(q)$. Such cases allow CRP participation to respond positively and negatively to variations in insurance subsidies. Insurance effects will be most evident on farms that closely reflect the model's assumption that land uses are limited to production and conservation. Farms in the Corn Belt, for example, embody the insurance-conservation trade-off because the margin between crop production and CRP is thin relative to regions with more land-use heterogeneity. In other words, the true effect of insurance on CRP participation will appear in areas plentiful in CRP-eligible land, having direct competition between CRP and row-crop production, and where the CRP enrollment constraint is non-binding.

In general, the eligibility constraint creates a limited dependent variable problem that one would ideally estimate with a censored regression model at the farm level. Because I estimate the CRP-insurance relationship using county-level data, however, the above conditions introduce the possibility of aggregation bias. Aggregating farms that are constrained in their CRP participation together with unconstrained farms may give the appearance of sufficient CRP engagement at the county level but will not take into consideration the limited responses that can be made on-farm. The true effect of insurance will emerge in counties where farms are homogenous in 
their ability to increase or decrease enrollment in CRP (i.e., where both CRPeligible land is plentiful and crop production competes directly with it for land use). In the Results section, I discuss how this type of aggregation bias may partially explain differences in effect sizes observed across U.S. farm production regions. ${ }^{9}$

\section{Data}

Data for this project come from the USDA Risk Management Agency, the USDA Farm Service Agency, the Chicago Board of Trade, the USDA National Agricultural Statistical Service, and the National Oceanic and Atmospheric Administration. Data are observed at the county level for the years 1989 to 2013. The chosen years span the enactment of four major crop-insurance policies that exogenously increased insurance participation (FCIRA of 1994, ad hoc rate increases, ARPA of 2000, and the 2008 Farm Bill) as well as 14 separate CRP General Sign-ups and four different national enrollment caps. The geographic scope of the study includes all 48 contiguous states. The USDA Risk Management Agency (RMA) operates the federal crop-insurance program and maintains thorough records of all crop-insurance policies sold since 1981. RMA reports these data at the county level and makes them publicly available through an online database. From RMA, I collected the number of acres insured, total premiums charged, and total government subsidies paid in each county by policy type. ${ }^{10}$

County-level CRP enrollment data come from the USDA Farm Service Agency (FSA), which provides county totals for acres retired and total rental fees paid every year. To determine the average CRP rental fee per acre, I simply divide total payments made in a county by the number of acres enrolled. I correct CRP rental rates for inflation using the Producer Price Index (PPI). I also observe the years in which a General Sign-up or Continuous Sign-up was offered between 1989 and 2013.11 Continuous Sign-up was made available in every year after 1996, while General Sign-ups occurred in 1989, 1991, 1992, 1995, 1997, 1998, 2000, 2003, 2004, 2006, and 2010-2013. The relevant

\footnotetext{
9 I will also point out the limitation of this model to capture long-run dynamic relationships. Enrollment in CRP is a 10- to 15-year commitment, meaning the associated benefits and opportunity costs accrue over this time horizon. Long-term land retirement may improve soil fertility, which could alter the decision to return land to production and the expected insurance benefits therein. Though I model the decision as a single-year optimization problem, long-term considerations are certainly at work in practice.

10 RMA aggregates all crop-insurance policy data for a given county year. Total premiums paid include both the portion paid by farmers and subsidies paid by FCIC.

11 CRP enrolls land through two main conventions. Under the General Sign-up, whole farms or fields enter the program through a competitive bidding process based on the Environmental Benefits Index (EBI). Continuous Sign-ups enroll small tracts of land to be devoted to specific conservation practices. General Sign-ups are scheduled irregularly by the USDA, while land can enter through Continuous Sign-Up at any time.
} 
measure of CRP participation over time is the total CRP acreage enrolled in a county. This number includes both acres enrolled through General and Continuous Sign-up conventions. I exclude counties from the dataset that have no CRP enrollment in any of the 25 years examined. ${ }^{12}$

Commodity prices play a key role in both land retirement and crop-insurance choices. Harvest prices are not known when crop-insurance policies and CRP contracts are established, so landowner decisions in each year are based on expectations. For insurance, RMA uses averages of December corn, November soybeans, and September wheat futures prices traded during the month of February to determine premiums and guarantees. ${ }^{13}$ I collect futures prices for corn, soybeans, and wheat from the Chicago Board of Trade through an online database made available by Quandl Inc. ${ }^{14}$ I take the average February settlement price for each futures contract for the years 1989 to 2013 and adjust for inflation using the PPI for each commodity. ${ }^{15}$ From the USDA National Agricultural Statistical Service (NASS) I collect the number of acres harvested of corn, soybeans, and wheat in each observed county from 1979 to 2013. From this I calculate a measure of each commodity's importance based on its percentage of total acres harvested over the previous 10 years. I then create a weighted average of all three futures prices as follows:

$$
P_{i t}=\sum_{j} \mu_{j i t} p_{j t}
$$

where

$$
\mu_{j i t}=\frac{\sum_{\tau=t-10}^{t-1} H_{j i \tau}}{\sum_{j} \sum_{\tau=t-10}^{t-1} H_{j i \tau}}
$$

The term $H_{j i \tau}$ represents the total acres harvested of crop $j$ in county $i$ during year $\tau$ for $j=$ corn, soybeans, and wheat. Missing values for crop production weights are replaced with averages for the state in which the county resides.

\footnotetext{
12 Only about six percent of counties with some insurance participation between 1989 and 2013 had zero CRP enrollment data for this time period. The exclusion of these counties was not found to affect estimation results.

${ }_{13}$ Losses on yield-based policies are indemnified at the relevant February futures price. Revenue policies are indemnified at the higher of the February futures price or the harvest price, unless the harvest price exclusion option is selected.

${ }_{14}$ Quandl provides data aggregation services from numerous sources. Commodity futures price data from the Chicago Mercantile Exchange can be accessed at https://www.quandl.com/data/ CME.

15 Producer Price Indices for corn, soybeans, and wheat for the month of February are used to adjust nominal futures prices. PPI data are taken from the St. Louis Federal Reserve FRED database.
} 
The National Oceanic and Atmospheric Administration (NOAA) publishes the Palmer Drought Severity Index (PDSI) at the state level for all contiguous states. The PDSI measures soil moisture levels using both current and previous conditions, making the PDSI a good indicator of long-run trends in precipitation. Positive values indicate wet conditions, while negative values correspond to drought. From annual average PDSI values I create an indicator variable equal to one in years when states experienced moderateto-extreme drought conditions. ${ }^{16}$

The compiled dataset includes 2,756 counties observed between 1989 and 2013 , for a total of 68,900 observations. Table 1 summarizes the variables described above for each of the relevant crop-insurance policy periods. The important policy changes that occurred during the observation period included the Federal Crop Insurance Reform Act of 1994 (FCIRA), ad hoc subsidy rate increases in 1998 and 1999, the Agricultural Risk Protection Act of 2000 (ARPA), and the 2008 Farm Bill. Each policy made meaningful changes to the schedule of crop-insurance subsidy rates for the purpose of increasing participation. Figures 1 and 2 depict the impact of these policy changes on different crop-insurance types, and Figure 3 shows the commensurate trend in overall crop-insurance participation between 1989 and 2013. The vertical dashed lines correspond to the passage of each of the four major policies. I consider a policy period the years between the passing of a given crop-insurance law and the enactment of a new policy.

Total acreage under federal crop insurance exhibits a general upward trend throughout the observation period, with large jumps occurring after FCIRA in 1994, ARPA of 2000, and the Farm Bill of 2008. Acres insured more than doubled after passage of the 1994 Act to over 70,000 acres per county. Trends in subsidy rates for various policy types illustrate the differential effects of the four policy changes. For example, because catastrophic insurance (CAT) carries a 50 percent coverage level, changes in subsidy rates for 50 and 55 percent policies reflect the full subsidization of CAT insurance brought about by FCIRA in 1994. Similarly, buy-up policies experience their largest increases in subsidy rates during the ad hoc and ARPA policy periods. Note that 80 percent policies and revenue-based policies do not enter the market until 1993 and 1996, respectively, so their subsidy rates are zero prior to the FCIRA policy period.

Average CRP enrollment rises and falls between 11,000 and 13,000 acres per county during the study period. National CRP enrollment was originally capped at 45 million acres but has changed over time to reflect budgetary conditions and policy goals. Figure 4 illustrates the trend in CRP participation and the total enrollment caps from 1989 to 2013. Enrollment increased gradually

\footnotetext{
16 PDSI values of $-2,-3$, and -4 correspond to moderate, severe, and extreme drought conditions, respectively. I create a dummy variable equal to one if the state PDSI is -2 or below in a given year.
} 
Table 1. Summary Statistics by Crop Insurance Policy Period

\begin{tabular}{|c|c|c|c|c|c|c|c|c|c|c|}
\hline \multirow[b]{3}{*}{ Variable } & \multirow{2}{*}{\multicolumn{2}{|c|}{$\frac{\text { Pre-FCIRA }}{1989-1994}$}} & \multirow{2}{*}{\multicolumn{2}{|c|}{$\frac{\text { FCIRA }}{1995-1998}$}} & \multirow{2}{*}{\multicolumn{2}{|c|}{$\frac{\text { Ad hoc }}{1999-2000}$}} & \multirow{2}{*}{\multicolumn{2}{|c|}{$\frac{\text { ARPA }}{2001-2008}$}} & \multirow{2}{*}{\multicolumn{2}{|c|}{$\frac{2008 \text { Farm Bill }}{2009-2013}$}} \\
\hline & & & & & & & & & & \\
\hline & Mean & $\begin{array}{l}\text { Std. } \\
\text { Dev. }\end{array}$ & Mean & $\begin{array}{l}\text { Std. } \\
\text { Dev. }\end{array}$ & Mean & $\begin{array}{l}\text { Std. } \\
\text { Dev. }\end{array}$ & Mean & $\begin{array}{l}\text { Std. } \\
\text { Dev. }\end{array}$ & Mean & $\begin{array}{l}\text { Std. } \\
\text { Dev. }\end{array}$ \\
\hline $\begin{array}{l}\text { Acres enrolled in | } \\
\text { CRP }(1,000 \text { s of } \\
\text { acres })\end{array}$ & 11.99 & 23.56 & 12.00 & 23.80 & 11.10 & 25.30 & 12.63 & 27.94 & 11.06 & 24.82 \\
\hline $\begin{array}{l}\text { CRP rent (\$ per } \\
\text { acre enrolled) }\end{array}$ & 44.84 & 11.90 & 41.73 & 13.20 & 39.81 & 18.83 & 37.39 & 21.01 & 34.20 & 20.03 \\
\hline $\begin{array}{r}\text { Total acres insured } \\
(1,000 \text { s of acres })\end{array}$ & 32.37 & 61.99 & 70.47 & 102.12 & 71.90 & 106.07 & 84.71 & 142.37 & 97.67 & 137.44 \\
\hline $\begin{array}{c}\text { Subsidy rate- } \\
50 \%-55 \% \\
\text { Coverage }\end{array}$ & 0.30 & 0.00 & 0.91 & 0.10 & 0.90 & 0.09 & 0.86 & 0.10 & 0.82 & 0.09 \\
\hline $\begin{array}{c}\text { Subsidy rate- } \\
60 \%-65 \% \\
\text { Coverage }\end{array}$ & 0.29 & 0.03 & 0.40 & 0.03 & 0.55 & 0.04 & 0.60 & 0.02 & 0.63 & 0.04 \\
\hline $\begin{array}{c}\text { Subsidy rate- } \\
70 \%-75 \% \\
\text { Coverage }\end{array}$ & 0.17 & 0.01 & 0.25 & 0.04 & 0.46 & 0.04 & 0.58 & 0.03 & 0.64 & 0.06 \\
\hline $\begin{array}{c}\text { Subsidy rate- } \\
80 \%-85 \% \\
\text { Coverage }\end{array}$ & 0.10 & 0.14 & 0.31 & 0.06 & 0.45 & 0.08 & 0.49 & 0.06 & 0.56 & 0.06 \\
\hline $\begin{array}{l}\text { Subsidy rate- } \\
\text { Revenue } \\
\text { policies }\end{array}$ & 0.00 & 0.00 & 0.27 & 0.17 & 0.48 & 0.06 & 0.58 & 0.04 & 0.64 & 0.07 \\
\hline
\end{tabular}




\begin{tabular}{|c|c|c|c|c|c|c|c|c|c|c|}
\hline $\begin{array}{l}\text { Palmer drought } \\
\text { severity index }\end{array}$ & 0.71 & 2.03 & 1.32 & 1.59 & -0.72 & 1.92 & -0.15 & 1.97 & 0.10 & 2.57 \\
\hline $\begin{array}{l}\text { Drought indicator } \\
\text { (PDSI }<-2 \text { ) }\end{array}$ & 0.10 & 0.30 & 0.00 & 0.01 & 0.30 & 0.46 & 0.18 & 0.39 & 0.23 & 0.42 \\
\hline $\begin{array}{l}\text { Dec. Corn price ( } \$ \\
\text { per bushel) }\end{array}$ & 2.59 & 0.18 & 2.51 & 0.26 & 2.93 & 0.10 & 2.87 & 0.27 & 2.43 & 0.35 \\
\hline $\begin{array}{l}\text { Nov. Soybeans } \\
\text { price (\$ per } \\
\text { bushel) }\end{array}$ & 6.09 & 0.28 & 5.84 & 0.29 & 6.21 & 0.13 & 5.93 & 0.58 & 5.63 & 0.28 \\
\hline $\begin{array}{l}\text { Sept. Wheat price } \\
\text { (\$ per bushel) }\end{array}$ & 3.52 & 0.27 & 3.33 & 0.22 & 3.56 & 0.08 & 3.39 & 0.28 & 3.67 & 0.13 \\
\hline Corn harvest (\%) & 0.38 & 0.32 & 0.39 & 0.31 & 0.39 & 0.30 & 0.39 & 0.29 & 0.39 & 0.28 \\
\hline $\begin{array}{l}\text { Soybeans harvest } \\
\text { (\%) }\end{array}$ & 0.27 & 0.26 & 0.26 & 0.25 & 0.27 & 0.24 & 0.28 & 0.25 & 0.30 & 0.25 \\
\hline Wheat harvest (\%) & 0.35 & 0.36 & 0.35 & 0.25 & 0.34 & 0.36 & 0.32 & 0.36 & 0.30 & 0.36 \\
\hline Expected price & 3.86 & 0.83 & 3.67 & 0.75 & 4.02 & 0.71 & 3.91 & 0.74 & 3.78 & 0.67 \\
\hline Observations & 16,536 & - & 11,024 & - & 5,512 & - & 22,048 & - & 13,780 & - \\
\hline
\end{tabular}

Notes: CRP rental rates are adjusted for inflation using annual averages of the Producer Price Index for all goods. Commodity futures prices are adjusted for inflation using the Producer Price Index specific to each commodity for the month of February.

Sources: CRP data come from USDA FSA statistics on CRP enrollment. Crop insurance data provided by USDA RMA data files. PDSI generated by state specific queries on NOAA Climate Monitoring website. Futures prices from the Chicago Board of Trade are made available by Quandl Inc. Crop harvest data downloaded from USDA NASS Quick Stats online database. Producer Price Indices for each commodity were retrieved from the St. Louis Fed FRED online database. 


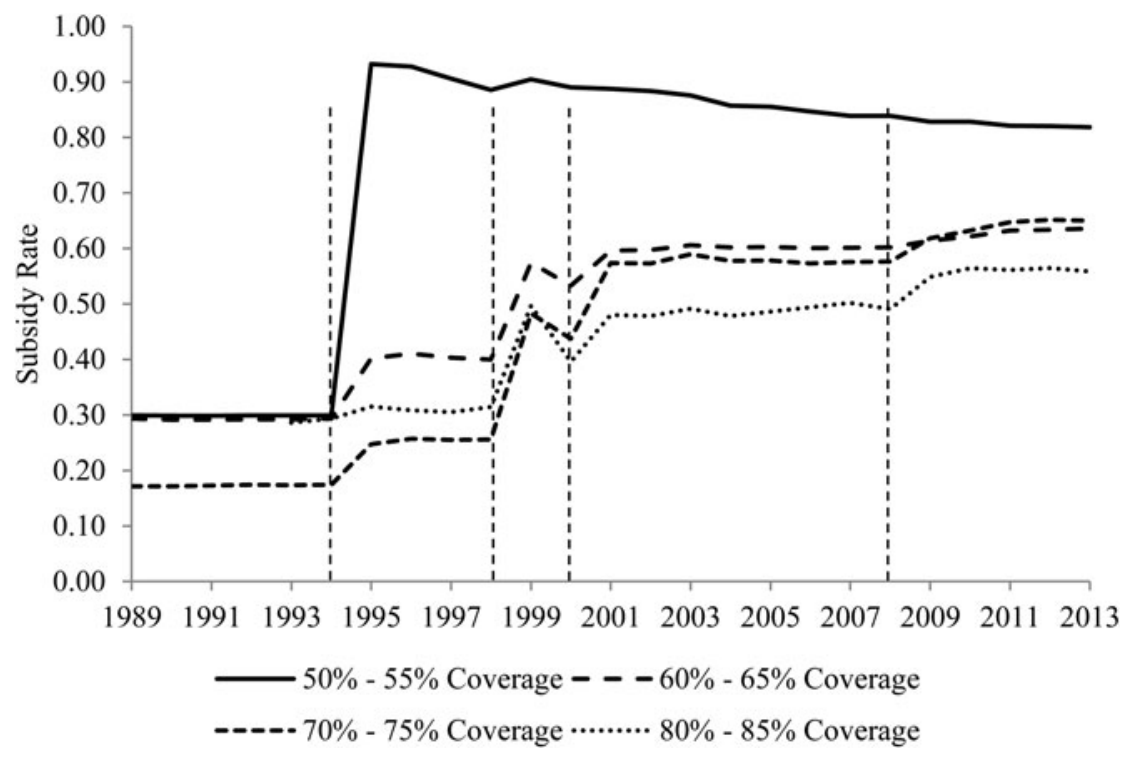

Figure 1. Crop Insurance Subsidy Rates by Coverage Level (1989-2013)

Source: USDA Risk Management Agency, Crop Insurance Statistics by County 1989-2013.

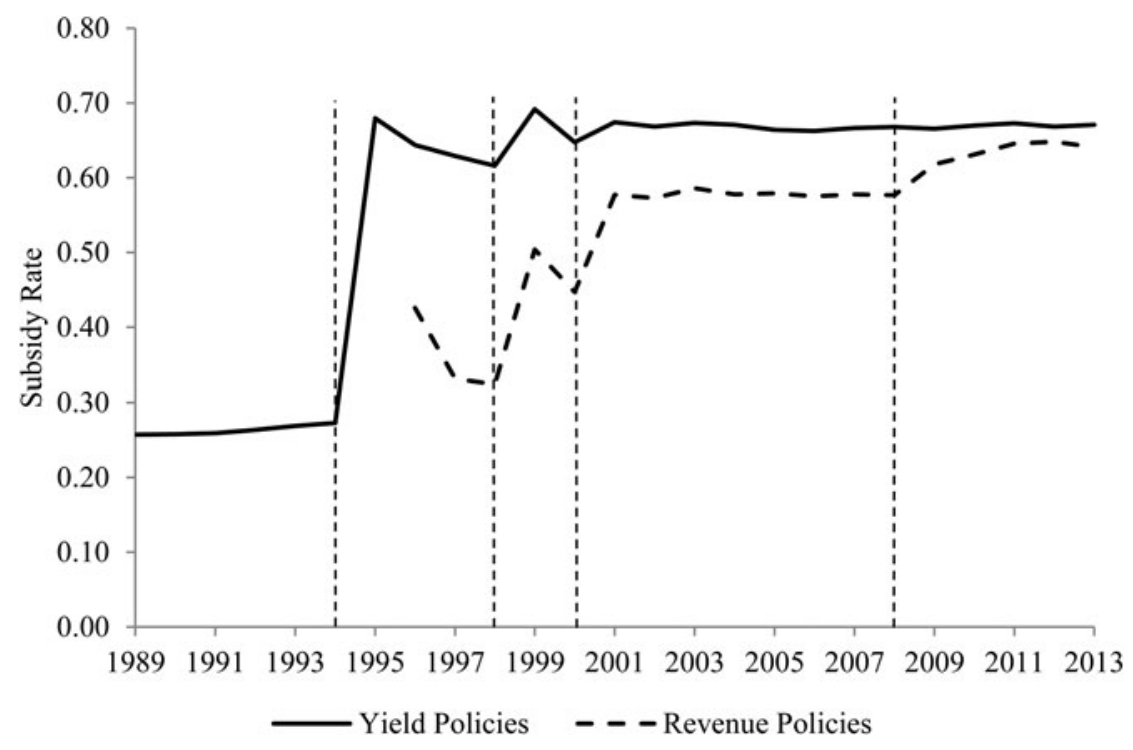

Figure 2. Crop Insurance Subsidy Rates by Policy Type (1989-2013)

Source: USDA Risk Management Agency, Crop Insurance Statistics by County 1989-2013. 


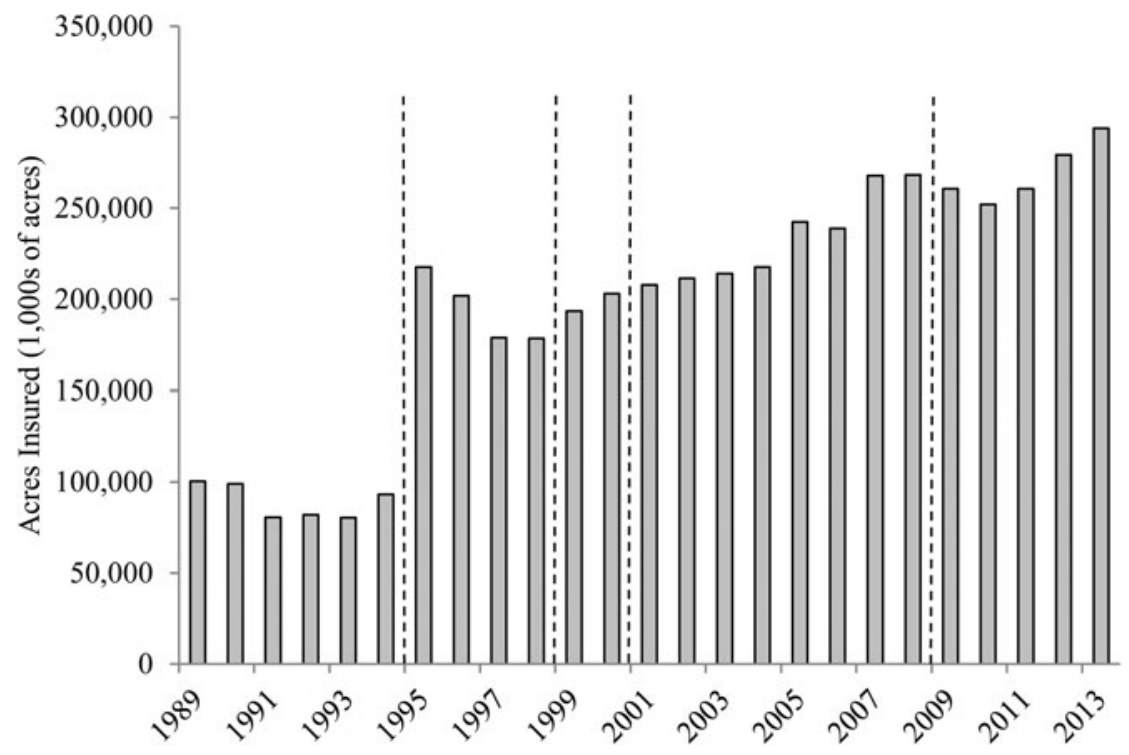

Figure 3. Total Acres Insured by Federal Crop Insurance (1989-2013)

Source: USDA Risk Management Agency, Crop Insurance Statistics by County 1989-2013.

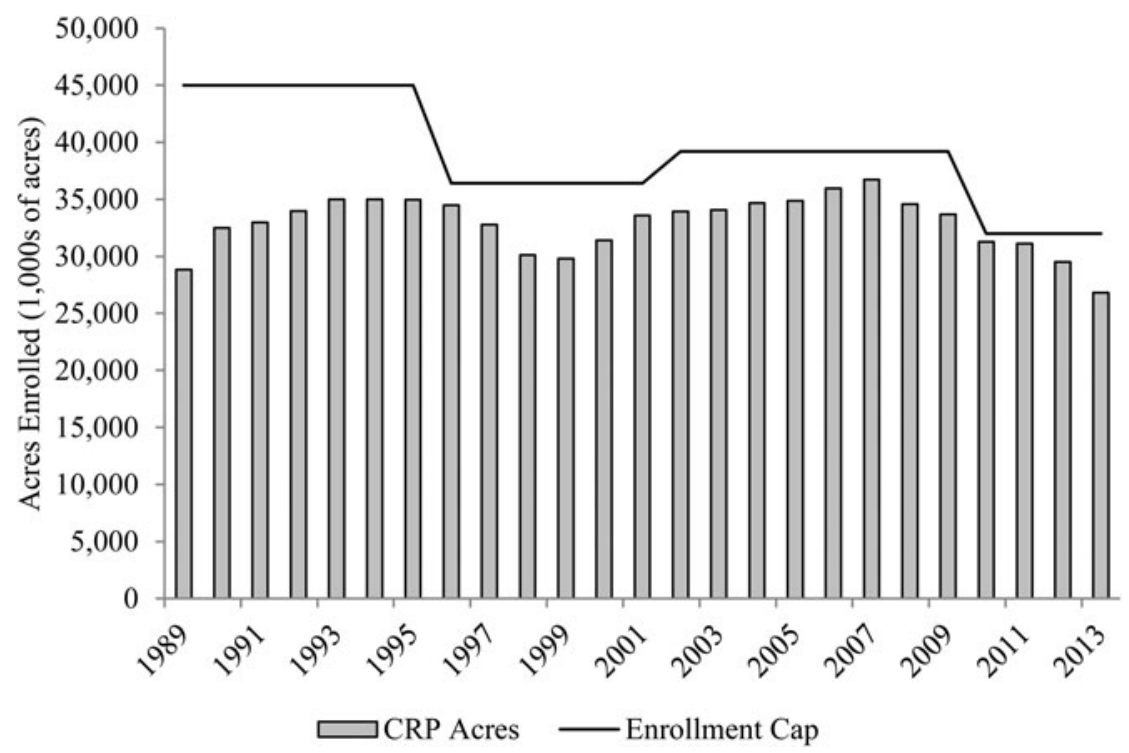

Figure 4. Total Acres Enrolled in CRP (1989-2013)

Source: USDA Farm Service Agency, CRP Statistics 1986-2014. 
until 1996 thanks to successful early General Sign-ups in 1989, 1991, and 1992, but suffered throughout the late 1990s despite the introduction of the Continuous Sign-up convention. Changes in total enrollment over time generally reflect the national enrollment cap, commodity prices, and climate (Claassen and Hellerstein 2008; Secchi et al. 2009; Rashford, Walker, and Bastian 2010; Hendricks and Er 2018).

Drought conditions are most widespread in 1999 and 2000 and from 2009 to 2013. ${ }^{17}$ Inflation adjusted futures prices for corn, soybeans, and wheat are also presented in Table 1 along with the historical proportion of acres harvested of each crop. Expected price refers to the production weighted average futures price as described above.

\section{Estimating the Impact of Crop Insurance on CRP}

The total number of CRP acres in any given year can be modeled as previous acres enrolled less exiting acreage plus new acres entering the program. The number of acres leaving the program can be expressed as a proportion of the total acres enrolled the year prior. Initially, I assume there is an average annual exit rate of $\delta$, which is constant over time and across counties. ${ }^{18}$ I test this assumption in Appendix B, showing that the exit (re-enrollment) rate is significantly higher (lower) during years when the national enrollment cap is low.

The total number of acres enrolled in CRP in county $i$ during year $t$ can be expressed as follows: ${ }^{19}$

$$
\mathrm{CRP}_{i t}=\mathrm{CRP}_{i t-1}-\delta \mathrm{CRP}_{i t-1}+\eta_{i t}\left(\text { Acres Insured }_{i t}, \boldsymbol{X}_{i t}, \alpha_{i}, \tau_{t}\right)
$$

Net new acres entering CRP in each year, represented by $\eta_{i t}$, is a function of the number of acres insured under federal crop insurance, Acres Insured ${ }_{i t}$, a vector of exogenous control variables that affect both insurance and conservation behavior, $\boldsymbol{X}_{i t}$, county fixed effects, $\alpha_{i}$, and year fixed effects, $\tau_{t}{ }^{20}$ The vector $\boldsymbol{X}_{i t}$

17 A drought and heat wave in 2000 severely affected much of the intermountain West, Southern Plains, and Southeastern states, while a more widespread drought occurred in 2012.

18 The true number of acres eligible to leave CRP is difficult to calculate. This is because after 1996, annual changes in CRP acreage includes both acres entering and leaving the program, but FSA data only provide the net change. This limitation makes it impossible to know exactly how many of the acres eligible for release from the program actually leave and how many contracts renew for an additional 10 to 15 years. To contend with this, I assume an average exit rate. Net new acres entering CRP, $\eta_{i t}$, captures periods of higher or lower than average exit from the program. As a robustness check, I test for differences in this exit rate under different national enrollment caps and across different farm production regions (see Appendix B).

19 Though I model CRP enrollment decisions at the representative producer level, county level data for both CRP and insurance use is the most disaggregated data available that is also easily accessible at this scale and scope.

20 Net new enrollments, $\eta_{i t}$, captures both acres entering the program for the first time and reenrollments of expiring contracts. Crop insurance and exogenous factors influence new 
includes CRP rental rates, expectations of drought, and expected commodity prices. County fixed effects control for regional characteristics such as soil quality and preferences for environmental amenities. Policy changes that impact all counties in each year, namely, the national CRP enrollment cap, are captured by year fixed effects. Assuming linear relationships between CRP participation and all explanatory variables, I estimate the following panel data fixed effects regression:

$$
\begin{gathered}
\mathrm{CRP}_{i t}=(1-\delta) \mathrm{CRP}_{i t-1}+\alpha_{i}+\tau_{t}+\psi \text { Rent }_{i t}+\beta \text { Acres Insured }_{i t} \\
+\theta \text { Drought }_{s t-1}+\phi P_{i t}+e_{i t}
\end{gathered}
$$

I first estimate a model without time controls as a baseline to compare with year fixed effects.

A primary incentive for producers to enter CRP is the per-acre rental rate, represented in the model by the variableRent ${ }_{i t}$, which should have a positive and significant impact on CRP participation. ${ }^{21}$ The estimate of the average CRP exit rate $\delta$ can be calculated by subtracting the estimated coefficient on lagged CRP acreage from one. To control for climate shocks that impact both CRP and crop-insurance decisions, I include a drought indicator. The variableDrought $_{s t-1}$ is a dummy variable equal to one if the county located in state $s$ has an average Palmer Drought Severity Index (PDSI) of negative two or below in year $t-1 .^{22}$ Lagged drought conditions represent expectations of future droughts which may positively or negatively affect CRP acreage, as poor growing conditions make risk-free CRP rental fees more attractive while at the same time increasing expected payouts from insurance. Weighted average commodity futures prices are represented by the variable $P_{i t}$. As CRP rental payments are fixed for the duration of the contract, high crop prices raise the opportunity cost of CRP. I expect futures prices to negatively impact CRP enrollment.

The right-hand side variable of interest is the total number of acres insured in county $i$ during year $t$. I predict that land insured under federal crop insurance crowds out potential new acres entering CRP and causes existing acres to exit the program. The magnitude of the effect, however, should be small, in accordance with previous literature (Young, Vandeveer, and Schnepf 2001;

enrollments as well as decisions to re-enroll. Therefore, $\eta_{i t}$ encompasses both enrollment deterrence effects and exit effects of crop insurance on CRP.

21 The variable Rent ${ }_{i t}$ is deflated using the PPI.

22 Producers likely use more than just the previous year to form expectations of future droughts. Various combinations of one-, two-, and three-year lags of drought conditions were tested. Main results are consistent across drought-variable combinations. Moreover, the PDSI measures longrun trends in precipitation, so the value at any point in time takes into account previous drought conditions. A single year lag of the severe drought dummy variable was chosen for simplicity of interpretation and parsimony. 
Goodwin, Vandeveer, and Deal 2004; Lubowski et al. 2006; Claassen, Langpap, and Wu 2017)

Endogeneity between insurance activity and CRP complicates the above specification. Producers make crop-insurance and land-retirement decisions jointly. Without an exogenous source of variation in insurance use, the estimated impact of insured acres on CRP will reflect this joint determination. Specifically, $\hat{\beta}$ may capture how CRP participation influences planting and insurance decisions. Moreover, equation 15 does not incorporate subsidies for crop insurance but only the total amount of insured acreage. The number of insured acres within a county may vary for many reasons unrelated to subsidization which are not the focus of this paper. An endogeneity issue also emerges in the CRP rental rate variable. Because the rental rate variable is calculated as an average for each county-year, acres enrolled in CRP enters both sides of the regression equation. If estimated as written, the relationship between acres enrolled and program compensation will be biased (likely in the downward direction).

I address these issues by employing an instrumental variables approach. Government policy exclusively sets the subsidy rates applied to each type of crop-insurance policy and coverage level. This schedule of subsidy rates has changed over time to encourage greater participation in the program and reduce the need for disaster assistance. I exploit increases in subsidy rates resulting from four major crop-insurance policy changes, the Federal Crop Insurance Reform Act of 1994 (FCIRA), ad hoc subsidy rate increases in 1998 and 1999, the Agricultural Risk Protection Act of 2000 (ARPA), and the 2008 Farm Bill. Figures 1 and 2 illustrate the impact of government policy changes (denoted by vertical dashed lines) on subsidy rates of different types of crop insurance. ${ }^{23}$ The impact of these policy changes can be seen clearly in Figure 3. A marked increase in acres insured follows the enactment of each piece of legislation, with the exception of the 2008 Farm Bill, which appears to have had a delayed effect on participation. ${ }^{24}$

I use dummy variables for each policy period (FCIRA, ad hoc, ARPA, and the 2008 Farm Bill) to instrument for changes in the number of acres insured. Policy indicators can explain within-county variation in acres insured over time but do not provide the spatial (between-county) variation necessary for proper instrumentation. Crop-insurance legislation is set at the national level, meaning every county in the dataset receives the policy "treatment" at the same time but may not receive it in the same way. A measure of the degree

\footnotetext{
23 Subsidy rates in the dataset are reported for groups of coverage levels as opposed to each individual coverage level (e.g., 60 percent and 65 percent plans are combined, and one rate is reported for both). This creates some variation in subsidy rates that is due to producer preferences and not government policy, though the variation is negligible.

$24 \mathrm{Yu}$, Smith, and Sumner (2018) perform a similar instrumental variables (IV) approach using changes in national crop insurance subsidy rates. I extend their IV strategy by exploiting spatial variation in policy-change exposure based on predetermined crop-insurance preferences.
} 
to which various policies affect a county is required. To do this, I measure preferences for different types of insurance prior to the enactment of each legislative change.

From Figure 1 we see that FCIRA of 1994 dramatically impacts subsidy rates for 50 and 55 percent policies, while "buy-up" plans (60 percent coverage and above) experience smaller but meaningful increases in subsidy rates. The large change in subsidy rates for low-coverage plans reflects the introduction of fully subsidized catastrophic coverage (CAT). To measure the extent to which the 1994 Act impacts a county, I calculate the percent of total cropland insured at each coverage level category (50-55 percent, 60-65 percent, 70-75 percent, and 80-85 percent) in the period prior to the enactment of FCIRA (1989 to 1994). ${ }^{25}$ This approach generates between-county variation in exposure to FCIRA subsidy rate increases that is unrelated to CRP decisions.

Ad hoc subsidy increases passed in 1998 and 1999 raise subsidy rates for buy-up and revenue plans (see Figures 1 and 2) but leave low-coverage and yield-based policies relatively unaffected. ARPA of 2000 added to these changes, and the Farm Bill of 2008 further increases rates for high-coverage products. I capture a county's exposure to these policy changes by calculating the percentage of cropland insured under each coverage level in the periods directly preceding the passage of each legislative change.

Insurance participation prior to each policy change is measured as a percentage of total cropland to control for the scale of production capacity in each county. The USDA calculates total cropland for each county as part of the Census of Agriculture every five years. I use acres of cropland in 1992 to calculate percentages of insured acres during the pre-FCIRA period, cropland in 1997 to calculate insurance percentages in the FCIRA and ad hoc policy periods, and cropland in 2002 for the ARPA period. ${ }^{26}$

To generate instruments for insured acres, I interact these policy-exposure measures with dummy variables representing each of the four policy change periods. $^{27}$ These interactions can be used to determine how much a county sees its effective subsidy rates increase and can be used to estimate the

25 The USDA defines total cropland as the total of harvested cropland, crop failure, cultivated summer fallow, cropland pasture, and idled cropland. This broad measure is used to calculate crop-insurance participation as a percentage, because it represents the total possible area in a county that could be insured.

26 The Census of Agriculture did not begin recording cropland acreage at the county level until 1997. The USDA Economic Research Service (ERS) records total annual cropland at the state level for years prior to 1997. To calculate county-level cropland for 1992, I find each county's proportion of total state cropland for Census years 1997, 2002, 2007, and 2012 and take a simple average. I then apply these average proportions to the total acres of state cropland for 1992 provided by ERS.

27 Though policy changes affect yield and revenue-type insurance as well as different coverage levels, I do not use preferences for yield and revenue insurance as policy-exposure instruments. This is due to high collinearity detected between coverage-preference instruments and insurance-type preference instruments. 
variation in insured acreage due only to changes in government policy and not to contemporaneous land-use decisions. Pre-policy exposure measures reflect a county's entrenched preferences for certain types of insurance. Therefore, when new legislation acts on these preexisting preferences, causing insurance participation to rise or fall, we can be confident that the resulting variation in acres insured is attributed only to exogenous government policy and not jointly determined CRP enrollment.

To provide further spatial variation in insurance use that is uncorrelated with conservation decisions, I include a one-year lag of acres insured as an additional instrument. While the policy-change instruments measure the impact of subsidy rate increases on insurance participation (demand response), lagged insurance use measures of a county's preference for crop insurance more generally. Lagged insured acres are highly predictive of future insurance use within a county but are predetermined with respect to current CRP enrollment (or exit) decisions.

Following a similar approach, I use a one-year lag of the county CRP rental rate to address the endogeneity between current rental rates and acres enrolled in CRP. This strategy resolves the downward bias in estimated rental rate effects that result from averaging total payments over the number of acres in CRP. CRP rental rates are made to reflect prevailing cash rental rates for non-irrigated farmland of different soil types. Because soil types are unchanged from year to year, lagged rates serve as strong predictors of future rates. Any remaining year-to-year fluctuations in CRP rent reflect changes in farm profitability (price and yield shocks) and government policy (maximum acceptable bids), which independently affect current CRP acreage decisions. Conditional on lagged CRP enrollment, drought expectations, commodity futures prices, and government policy (year fixed effects), prior CRP rental rates will be correlated with current rental rates but uncorrelated with the error term in equation 15. Lagged CRP rental rates are therefore a valid IV for present rental rates.

I perform a two-stage least squares (2SLS) regression using Stata's XTIVREG2 command, which accommodates both instrumental variables and clustering of standard errors. First-stage regression equations predict current insurance participation and CRP rental rates using policy-period dummies, policyexposure measures, lagged-acres insured, lagged-CRP rental rates, and all exogenous covariates shown in equation 15. In the second-stage regression, predicted values for acres insured and rental rates take the place of the endogenous regressors. See Appendix A for a detailed explanation of the instrumental variables calculation and first-stage regression for insured acreage. Standard errors are clustered at the state level as opposed to the county level following Cameron, Gelbach, and Miller (2011). ${ }^{28}$

28 Cameron, Gelbach, and Miller (2011) show that for the nested clusters, it is best to aggregate to the highest level possible while maintaining enough clusters for estimation. I find that standard 


\section{Results}

Regression results with county fixed effects and instrumental variables are reported in Table $2 .^{29}$ Specification (1) of Table 2 does not include time controls, while (2) applies year fixed effects to capture the impact of changes in the national enrollment cap. $\mathrm{R}^{2}$ values in both specifications indicate the models fit the data well overall, and first stage F-statistics show strong relevance of instruments to endogenous variables.

As expected, the estimated effect of CRP rent is positive and highly significant in both specifications. A one-dollar increase in real CRP rental rates boosts CRP participation by 25 to 33 acres per county. At the median, this effect implies an elasticity of 0.37 to 0.49 percent. $^{30}$ The model indicates that, on average, 88 percent of existing CRP acres in a county remain in the program from year to year, implying an average exit rate of 12 percent per year.

Enrollment in CRP increases substantially if a drought was present in the previous year, though the estimated coefficient is not statistically significant when year fixed effects are applied. Column (1) of Table 2 shows that a statewide drought increases CRP enrollment by an estimated 314 acres per county. The effect of drought expectations remains positive after including temporal controls but becomes statistically insignificant. Drought conditions are spatially correlated across large parts of the United States during the study period. Because I measure drought as a zero-one dummy variable, year fixed effects absorb much of the variation in the drought variable, leading to the lack of statistical significance in specification (2). ${ }^{31}$

The first specification of Table 2 reports a positive and statistically significant coefficient for commodity futures prices but a negative and significant coefficient when year fixed effects are introduced. Specification (1) contradicts much of the literature showing that high commodity prices raise the opportunity cost of land retirement and remove acreage from programs like CRP. The way futures prices are weighted may explain the discrepancy. The mix of corn, soybeans, and wheat production does not vary drastically over time within counties (see commodity harvest percentages in Table 2). Because futures prices on the Chicago Board of Trade apply to all counties nationwide, the price variable could be picking up non-price-related factors that vary across time but not between counties. Specifically, as pointed out by

\footnotetext{
errors are significantly larger when clustering at the county level, which may produce a Type I error in testing coefficient significance.

29 A Hausman test to compare the performance of random and fixed effects confirms that a fixed effects model is preferable.

30 CRP acreage is highly skewed with a mean of 11,938 vs. a median of 2,463 . Evaluating rentalrate elasticities at the median provides a more appropriate estimate.

31 Using a lag of the actual PDSI in place of a drought indicator variable shows a statistically significant relationship between climate and CRP enrollment in models with year fixed effects (see Appendix B).
} 
Table 2. The Relationship Between Crop Insurance Participation and Enrollment in the Conservation Reserve Program (CRP)

IV Fixed Effects

(1)

Acres Enrolled in CRP

\begin{tabular}{|c|c|c|c|c|}
\hline \multirow[b]{3}{*}{ Variable } & \multirow{2}{*}{\multicolumn{2}{|c|}{ Acres Enrolled in CRP }} & \multirow{2}{*}{\multicolumn{2}{|c|}{ Acres Enrolled in CRP }} \\
\hline & & & & \\
\hline & Coef. & Std. Error & Coef. & Std. Error \\
\hline CRP rent ( $\$$ per acre enrolled) & $32.977^{* * *}$ & $(10.264)$ & $25.365^{* * *}$ & $(8.025)$ \\
\hline CRP acres lag & $0.878^{* * *}$ & $(0.011)$ & $0.881^{* * *}$ & $(0.011)$ \\
\hline Acres insured & $-0.004^{* *}$ & $(0.002)$ & $-0.003^{* *}$ & $(0.001)$ \\
\hline Drought & $313.558^{* *}$ & $(154.704)$ & 163.736 & $(169.556)$ \\
\hline Expected price & $178.419^{* * *}$ & $(51.025)$ & $-233.980 * *$ & $(101.076)$ \\
\hline Year fixed effects & No & - & Yes & - \\
\hline Observations & 68,900 & - & 68,900 & - \\
\hline Counties & 2,756 & - & 2,756 & - \\
\hline $\begin{array}{l}\text { First stage F-Statistic (Acres } \\
\quad \text { Insured) }\end{array}$ & 582.35 & - & $1.80 \times 10^{5}$ & - \\
\hline First stage F-Statistic (CRP Rent) & 793.73 & - & $4.08 \times 10^{5}$ & - \\
\hline R-Square & 0.80 & - & 0.81 & - \\
\hline
\end{tabular}

Notes: ${ }^{* * *} \mathrm{p}<0.01,{ }^{* *} \mathrm{p}<0.05,{ }^{*} \mathrm{p}<0.1$. Estimates generated using Two Stage Least Squares regressions with county fixed effects. Standard errors clustered at the state level are shown in parenthesis. Drought is an indicator equal to 1 if the PDSI was less than -2 in the previous year to reflect producer expectations. CRP rental payments are expressed in real terms using the PPI. Futures prices for corn (Dec.), soybeans (Nov.), and wheat (Sep.) are converted to real terms and weighted by historical production of each commodity over the previous 10 years.

Roberts and Schlenker (2013), unobserved shifts in anticipated production can influence commodity price futures, which can bias estimated supply elasticities. The inclusion of year fixed effects captures unobserved, large-scale shifts in retired cropland that affect harvest-time futures prices. ${ }^{32}$ Once yearly fixed effects are applied, the true effect of price expectations can come through. According to column (2) of Table 2, a one-dollar increase in average futures

32 One such shift could be the influence of government policy. Hendricks and Er (2018) point out that the government often manages national CRP enrollment for the purpose of influencing commodity prices. The positive correlation between futures prices and CRP enrollment found by the model without year fixed effects could reflect periods when the government raises the enrollment cap, thus taking acres out of production and raising harvest-time futures prices. 
prices removes 234 acres per county from CRP, suggesting a median elasticity of -0.36 percent.

The estimated coefficients on insured acres are statistically significant at the 0.05 significance level under both specification strategies. Instrumental variable results suggest that an additional acre insured in response to higher subsidies decreases the number of acres enrolled in CRP by between 0.003 and 0.004 . Put another way, a 1,000-acre increase in the number of acres insured in a county will reduce the number of acres enrolled in CRP in that county by three to four acres. The estimated effects of most explanatory variables in the model are sensitive to the inclusion of year fixed effects which capture CRP policy changes at the national level. Without year fixed effects, the impact of national administrative decisions are channeled indirectly through the covariates of the model. Examining the coefficients on each year dummy variable (suppressed in results tables) confirms work by Hendricks and Er (2018), who show that government policy, specifically changes in the national enrollment cap, exerts significant influence over CRP participation over time. Year dummy coefficients generally reflect the trend in the national cap.

Given the impact of year fixed effects on model estimates, I consider the -0.003 insurance effect to be the more reliable of the two estimates. I base all further applications of the estimated crowding out effect on this value. Computed at the median of insured acres and CRP enrollment, the associated elasticity implies that a one percent increase in acres insured under federally subsidized crop insurance reduces the number of acres in CRP by 0.03 percent. ${ }^{33}$

To check for regional differences in crowding out effects, I estimate the IV model with year fixed effects separately for each of the ten farm production regions (see Figure 5). Table 3 displays the point estimates for the effect of acres insured on CRP enrollment and their associated elasticities by farm production region. Standard errors are clustered at the county level as opposed to the state level due to a limited number of states in several of the production regions.

Crop insurance acreage effects are negative and statistically significant in five of the 10 production regions (Northern Plains, Great Lakes, Corn Belt, Appalachia, and the Southeast) but vary in magnitude from -0.006 to -0.019 . Evaluated at the median of the data for each region, these effects translate into losses of between 0.05 and 0.13 percent of CRP acres resulting from a one-percent increase in insurance participation. Large commodity-producing states in the Midwest and Northern Plains have elasticities at or near 0.10 percent at the median, while Appalachian and Southeastern states are closer to 0.05.

\footnotetext{
33 The median number of acres insured and median CRP enrollment across all counties and years is 20,565 acres per county and 2,463 acres per county, respectively. Computing elasticities at the median is most appropriate for this dataset due to the high variance in both CRP and insurance use.
} 


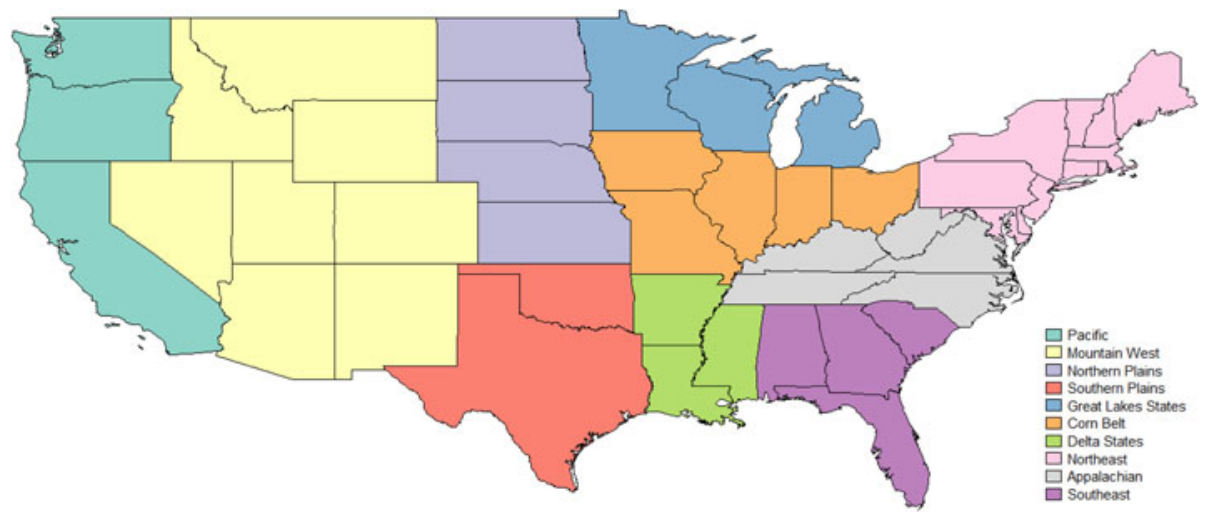

\section{Figure 5. USDA Farm Production Regions}

Source: USDA Economic Research Service, Major Uses of Land in the United States, 2012.

Elasticities vary greatly over the distribution of insurance acreage within regions. In the Great Lakes region, for example, a one-percent increase in insured acres reduces CRP acreage by 0.35 percent for a county at the 75 th percentile of insurance use and the median for CRP enrollment vs. 0.03 percent for a county at the 25 th percentile of insurance use. CRP losses range from 0.03 percent in the lower tail of the insurance distribution to 0.2 percent in the upper tail for counties in the Corn Belt. These estimates are significantly larger than those found by Claassen, Langpap, and Wu (2017), who predict that the presence of crop insurance in the Corn Belt reduces acreage in CRP by a mere 0.42 percent compared to a no-insurance baseline but are more in line with recent work by Yu, Smith, and Sumner (2018), who find larger acreage responses to crop-insurance subsidization than previous literature.

Relative to the upper Midwest, Appalachian and Southeastern states display lower crowding-out elasticities at the median but have similarly varied effect sizes across their respective insurance acreage distributions. The relationship between insurance and CRP is the least varied in the Northern Plains. However, CRP enrollment in the Northern Plains has declined significantly in recent years, while insurance use has remained high, making potential losses in CRP due to even small increases in insurance larger in percentage terms than are implied by Table 3 . Using the most recent data available for Northern Plains counties in 2017, a one-percent increase in insured acres would reduce CRP by 0.2 percent per county. ${ }^{34}$ Crop insurance participation

\footnotetext{
34 The estimated percentage loss in CRP is computed using the median acres insured $(224,493)$
} and median CRP enrollment $(9,934)$ for counties in the Northern Plains during the year 2017. 
Table 3. The Effect of Insured Acres on CRP Enrollment by Farm Production Region

\begin{tabular}{|c|c|c|c|c|c|}
\hline \multirow[b]{2}{*}{$\begin{array}{l}\text { Farm Production } \\
\text { Region }\end{array}$} & \multirow[b]{2}{*}{ Coef. } & \multirow[b]{2}{*}{$\begin{array}{l}\text { Std. } \\
\text { Error }\end{array}$} & \multicolumn{3}{|c|}{ Elasticities (\%) } \\
\hline & & & $\begin{array}{l}\text { 25th } \\
\text { percentile }\end{array}$ & $\begin{array}{l}\text { 50th } \\
\text { percentile }\end{array}$ & $\begin{array}{l}\text { 75th } \\
\text { percentile }\end{array}$ \\
\hline Pacific $(C A, O R, W A)$ & 0.002 & $(0.002)$ & 0.000 & 0.019 & 0.323 \\
\hline $\begin{array}{l}\text { Mountain }(I D, M T, \\
\quad W Y, N V, U T, C O, \\
A Z, N M)\end{array}$ & -0.000 & $(0.001)$ & 0.000 & 0.000 & 0.000 \\
\hline $\begin{array}{l}\text { Northern Plains } \\
\qquad(N D, S D, N E, K S)\end{array}$ & $-0.009^{* * *}$ & $(0.002)$ & $-0.041^{* * *}$ & $-0.084^{* * *}$ & $-0.126^{* * *}$ \\
\hline $\begin{array}{l}\text { Southern Plains } \\
\qquad(O K, T X)\end{array}$ & -0.000 & $(0.001)$ & 0.000 & 0.000 & 0.000 \\
\hline $\begin{array}{l}\text { Lake States (MN, } W I \text {, } \\
\quad M I)\end{array}$ & $-0.012^{* * *}$ & $(0.002)$ & $-0.026^{* * *}$ & $-0.131^{* * *}$ & $-0.347^{* * *}$ \\
\hline $\begin{array}{l}\text { Corn Belt }(I A, M O, \\
\quad I L, I N, O H)\end{array}$ & $-0.007^{* * *}$ & $(0.001)$ & $-0.030^{* * *}$ & $-0.106^{* * *}$ & $-0.203^{* * *}$ \\
\hline $\begin{array}{l}\text { Delta States }(A R, L A \text {, } \\
\quad M S)\end{array}$ & 0.001 & $(0.001)$ & 0.000 & 0.002 & 0.014 \\
\hline $\begin{array}{l}\text { Northeast (NY, VT, } \\
\quad N H, M E, M A, C T, \\
D E, R I, N J, P A, \\
M D)\end{array}$ & -0.003 & $(0.003)$ & -0.008 & -0.034 & -0.121 \\
\hline $\begin{array}{l}\text { Appalachia (VA, WV, } \\
\quad N C, K Y, T N)\end{array}$ & $-0.006^{* * *}$ & $(0.001)$ & $-0.009^{* * *}$ & $-0.062^{* * *}$ & $-0.306^{* * *}$ \\
\hline $\begin{array}{l}\text { Southeast }(A L, G A, \\
\quad S C, F L)\end{array}$ & $-0.019^{* * *}$ & $(0.004)$ & $-0.003^{* * *}$ & $-0.047^{* * *}$ & $-0.211^{* * *}$ \\
\hline
\end{tabular}

Notes: ${ }^{* * *} \mathrm{p}<0.01,{ }^{* *} \mathrm{p}<0.05{ }^{*} \mathrm{p}<0.1$. Point estimates of the effect of insured acres on acres enrolled in CRP were generated using Two Stage Least Squares regressions with county and year fixed effects. Standard errors are clustered at the county level as opposed to the state level due to the small number of states in several of the farm production regions. Associated elasticities are computed at the 25 th, 50th, and 75th percentiles of insured acreage and the median CRP enrollment for each region.

does not appear to crowd out CRP in the Pacific, Mountain West, Southern Plains, Mississippi Delta, or Northeastern farm production regions.

\section{Discussion}

I find that expanding crop insurance use by 1,000 acres via government policy reduces CRP enrollment by about three acres on average. A one-percent

These data were retrieved from RMA Summary of Business tables and CRP enrollment tables published by FSA. 
increase in insurance use draws down CRP participation by a modest 0.03 percent. Goodwin, Vandeveer, and Deal (2004) predict that an additional acre insured brings between 0.09 and 0.6 acres into production, depending on the crop being insured. My results indicate that a portion of this expansion, between 0.5 and three percent depending on crop type, occurs on land eligible for, or currently in, CRP.

According to the Food and Agricultural Policy Research Institute (FAPRI), soil runoff falls by 99 percent when land enters CRP compared to crop production. Enrollment in CRP reduces water erosion of soils by 2.13 tons per acre, nitrogen runoff by $7.73 \mathrm{lbs}$. per acre, and phosphorus runoff by $1.67 \mathrm{lbs}$. per acre (FAPRI 2007). Based on my estimates, a one-percent increase in national crop insurance use would increase soil erosion by nearly 20,000 tons, nitrogen loss by over $72,000 \mathrm{lbs}$, and phosphorus loss by about $16,000 \mathrm{lbs}$. per year nationwide. ${ }^{35}$ For context, these losses only represent about 0.03 percent of the erosion and nutrient runoff benefits conferred by CRP nationally. ${ }^{36}$ Put another way, a doubling of total insured acreage nationwide would only offset about three percent of the annual water-quality improvements generated by CRP.

The broader environmental costs implied in this study are small but consistent with existing research. Nevertheless, policymakers should be aware of all potential environmental consequences associated with subsidizing crop insurance. Soil erosion creates nutrient runoff which contaminates downstream water sources (e.g., Lake Erie and the Gulf of Mexico) and generates an externality in agricultural input use not borne by producers. Conservation requirements tied to farm support programs have been effective tools for dealing with this issue (Claassen et al. 2017). Since the passage of the 1985 Food Security Act, producers growing on highly erodible land must implement a conservation system to maintain eligibility for federal programs such as price support and disaster payments. Crop insurance premium subsidies were recently added to the list of support programs lost if found in violation of conservation requirements.

Compliance requirements could be extended to specifically target acreage exiting CRP to be planted and insured under federal crop insurance. Because CRP soil characteristics and practices vary by region, conservation requirements are best determined at the state or local level. In this way, I echo the conclusion arrived at by Walters et al. (2012) that uniform national

\footnotetext{
35 These figures are computed by taking one percent of the total number of acres insured nationwide for the most recent crop year (2017) and multiplying by the estimated crowdingout effect of -0.003 shown in Table 2, which comes to 9,348 acres removed from CRP (less than 0.04 percent of total 2017 enrollment). I then multiply this value by the per acre erosion, nitrogen, and phosphorus benefits reported by FAPRI (2007).

36 FAPRI (2007) estimate that CRP prevents 71 million tons of soil erosion, 259 million lbs. of nitrogen runoff, and 56 million lbs. of phosphorus runoff from contaminating water sources every year.
} 
policy recommendations are not an appropriate prescription. States could offer insurance premium cost-shares for producers that retain their most environmentally sensitive cropland in retirement. This could be done through a Continuous CRP Sign-up or by enrolling in the Conservation Reserve Enhancement Program (CREP) which partners with state governments. Furthermore, when insuring land that has been out of production for an extended period, producers use transitional yields (T-yields) equal to a percentage of the historical county average to define policy guarantees. Tyields used for land coming out of CRP could be adjusted further to reflect local productivity expectations, as detailed in the expiring CRP contract. ${ }^{37}$

I find that the impact of crop insurance on CRP varies by U.S. farm production region (see Table 3). As such, the consequences of CRP crowd-out will be regionally heterogeneous. For example, the Northern Great Plains contains much of the Prairie Pothole Region, an area where CRP contributes greatly to waterfowl habitat. Nielson et al. (2008) estimate that a mere four percent increase in CRP acreage leads to a 22 percent rise in pheasant counts, suggesting that even small changes in CRP due to crop insurance can have large impacts on wildlife. Financial consequences may also follow given the economic importance of recreational bird hunting in the Prairie Pothole Region. Hunting on CRP land contributes $\$ 99$ million to the economies of North and South Dakota annually. A 50 percent reduction in CRP enrollment in the Dakotas would cut the economic contribution of hunting by an estimated \$39 million (Loomis, Haefele, and Hill 2015). However, increased economic activity resulting from greater crop production would likely offset some losses in hunting revenue (Bangsund, Leistritz, and Hodur 2002).

Encroachment of insured land into CRP is most pronounced in the Northern Plains, Great Lakes states, and the Corn Belt, with more modest crowding out detected in Appalachia and the Southeast. Two forces may be driving the regional differences in effect sizes. First, aggregation bias could attenuate effects in regions where CRP eligibility is exogenously low. In addition to government policy, regional heterogeneity in land type and quality determines the amount of land eligible for retirement into CRP. Where eligibility is low, such as in Pacific and Northeastern states, a limited subset of producers is eligible for and participates in CRP. The negative effect of insurance on CRP will be present only among this limited subset of participants. The overall effect will be biased toward zero, however, as it is averaged over all insured producers in the county, many of whom have no acreage in CRP to begin with. A producer or farm-level analysis that controls for the limited dependent variable nature of CRP enrollment could improve

\footnotetext{
37 Targeted conservation compliance requirements and T-yield adjustments made for a specific plot could be based on the land and soil quality information contained in the expiring CRP contract.
} 
regional precision in these estimates. ${ }^{38}$ I consider this a direction for future work.

The second factor is land-use heterogeneity. Because the program specifically targets marginal cropland, expansion of crop production in regions with multiple competing land uses may occur at the expense of practices other than conservation (e.g., grassland pasture). We would not expect to find large effects in livestock grazing regions such as the Mountain West or Southern Plains. Conversely, we should expect insurance to impact CRP in regions where land retirement presents an immediate trade-off with crop production. High soil productivity, favorable climate, and topography make crop production highly profitable in the Northern Plains, the Great Lakes states, and the Corn Belt. As a result, cropland is the dominant land use in these regions (Bigelow and Borchers 2017). ${ }^{39}$

\section{Conclusion}

Much of the literature on federal crop insurance shows that greater participation leads to small positive effects on acreage planted to insured crops. Environmental consequences could follow if land brought under cultivation is environmentally sensitive. Crop-insurance subsidies reduce the cost of insurance to producers, thereby increasing the expected returns from insurance and encouraging production on marginal farmland. While many papers address the environmental effects of crop insurance, less attention has been paid to the relationship between federally subsidized crop insurance and the Conservation Reserve Program (CRP).

As America's largest and most successful land retirement program, CRP prevents soil erosion and chemical runoff, enhances wildlife habitat, and contributes recreational amenities enjoyed by the public. Government policies may come into conflict, however, if subsidies for crop insurance deter enrollment in conservation programs. I directly estimate this crowding out of CRP by crop insurance using a comprehensive panel dataset covering over 2,700 counties and spanning 25 years.

To contend with the inherent endogeneity between crop insurance and landretirement decisions, I exploit four major changes in government policy toward crop insurance during the 1990s and 2000s and apply a Two Stage Least Squares (2SLS) approach. Results indicate that a 1,000-acre increase in cropinsurance participation due to government policy crowds out about three

\footnotetext{
38 The distributional assumptions required by micro-level limited dependent variable models such as the Tobit often invite misspecification. Aggregated models, like the one used in this study, typically involve less burdensome assumptions and provide consistent estimators (Hellerstein, 1995).

39 Fifty-five percent of all land in the Corn Belt is devoted to crop production compared to seven percent in the Mountain West.
} 
acres from CRP on average. This translates to a -0.03 percent decrease in CRP for every one percent increase in insured acres (evaluated at the median).

Estimated effects are generally robust to various specifications and time periods but vary substantially by region. Heterogeneity in land quality and use determines regional effects. High field crop production areas of the Northern Great Plains, Great Lakes states, and the Corn Belt are susceptible to the largest crowding-out effects. Combining the instrumental variables technique used in this study with a farm-level model that corrects for the limited dependent variable nature of CRP enrollment may improve estimate precision. Such an approach would correct for any aggregation-bias attenuating effects in areas with low CRP eligibility.

While the environmental consequences of converting land from CRP to insured crop production may be large at a local level (enrolling land in CRP reduces soil runoff by 99 percent), the overall environmental effects appear small. I estimate that a one-percent increase in crop-insurance acreage nationwide would reduce the benefits generated by CRP by a mere 0.03 percent annually. Regional heterogeneity in effect sizes implies policy interventions are best designed at the state or local level.

\section{Supplementary material}

The supplementary material for this article can be found at https://doi.org/10. 1017/age.2019.9

\section{References}

Bangsund, D.A., F.L. Leistritz, and N.M. Hodur. 2002. "Rural Economic Effects of the Conservation Reserve Program in North Dakota." Agribusiness and Applied Economics Report No. 497. Dept. of Agribusiness and Applied Economics, North Dakota State University, Fargo, ND.

Cameron, A.C., J.B. Gelbach, and D.L. Miller. 2011. "Robust Inference with Multiway Clustering." Journal of Business and Economic Statistics 29(2): 238-249.

Chang, H.H., and R.N. Boisvert. 2009. "Distinguishing between Whole-Farm vs. Partial-Farm Participation in the Conservation Reserve Program." Land Economics 85(1): 144-161.

Claassen, R., C. Langpap, and J. Wu. 2017. "Impacts of Federal Crop Insurance on Land Use and Environmental Quality." American Journal of Agricultural Economics 99(3): 592-613.

Coble, K., T. Knight, R. Pope, and J. Williams. 1997. "An Expected Indemnity Based Approach to the Measurement of Moral Hazard in Crop Insurance." American Journal of Agricultural Economics 79(1): 216-226.

Congressional Research Service, " Conservation Reserve Program (CRP): Status and Issues," M. Stubbs. Congressional Research Service Report 42783, Washington, DC: Congressional Research Service, 2014.

Food and Agricultural Policy Research Institute, "Estimating water quality, air quality, and soil carbon benefits of the Conservation Reserve Program." FAPRI -UMC Report \#0107, Columbia, MO: University of Missouri, 2007.

Feng, H., D.A. Hennessy, and R. Miao. 2013. “The Effects of Government Payments on Cropland Acreage, Conservation Reserve Program Enrollment, and Grassland Conversion in the Dakotas." American Journal of Agricultural Economics 95(2): 412-418. 
Ferris, J., and J. Siikamaki. 2009. Conservation Reserve Program and Wetland Reserve Program: Primary Land Retirement Programs for Promoting Farmland Conservation. Washington, DC: Resources for the Future.

Glauber, J.W., and K.J. Collins. 2002. "Crop Insurance, Disaster Assistance, and the Role of the Federal Government in Providing Catastrophic Risk Protection." Agricultural Finance Review 62(2): 81-101.

Goodwin, B.K., and V.H. Smith. 2013. "What Harm is Done by Subsidizing Crop Insurance?" American Journal of Agricultural Economics 95(2): 489-497.

Goodwin, B.K., M.L. Vandeveer, and J.L. Deal. 2004. "An Empirical Analysis of Acreage Effects of Participation in the Federal Crop Insurance Program." American Journal of Agricultural Economics 86(4): 1058-1077.

Heimlich, R., D. Gadsby, R. Claassen, and K. Wiebe. 2003. "Wetlands Programs." In R. Heimlich, ed., Agricultural Resources and Environmental Indicators. Agriculture Handbook No. AH722.

Hellerstein, D. 1995. "Welfare Estimation Using Aggregate and Individual-Observation Models: A Comparison Using Monte Carlo Techniques." American Journal of Agricultural Economics 77(3): 620-630.

Hendricks, N., and E. Er. 2018. "Changes in Cropland Area in the United States and the Role of CRP." Food Policy 75(1): 15-23.

Ifft, J., D. Rajagopal, and R. Weldzius. 2018. "Ethanol Plant Location and Land Use: A Case Study of CRP and the Ethanol Mandate." Applied Economic Perspectives and Policy 119. doi: $10.1093 /$ aepp/ppy007.

Ifft, J., S. Wu, and T. Kuethe. 2014. "The Impact of Pasture Insurance on Farmland Values." Agricultural and Resource Economics Review 43(3): 390-405.

Just, R.E., and R.D. Pope. 1979. "Production Function Estimation and Related Risk Considerations." American Journal of Agricultural Economics 61(2): 279-284.

Loomis, J., M. Haefele, and R. Hill. 2015. "Economic Contributions, Impacts, and Economic Benefits of Deer, Waterfowl and Upland Game Bird Hunting in North and South Dakota: Relationship to CRP Lands." Colorado State University, Fort Collins, CO.

Miao, R., H. Feng, D.A. Hennessy, and X. Du. 2016. "Assessing Cost-Effectiveness of the Conservation Reserve Program (CRP) and Interactions Between the CRP and Crop Insurance." Land Economics 92(4): 593-617.

Miao, R., D.A. Hennessy, and H. Feng. 2016. "The Effects of Crop Insurance Subsidies and Sodsaver on Land-Use Change." Journal of Agricultural and Resource Economics 41(2): 247-265.

Nielson, R.M., L.L. McDonald, J.P. Sullivan, C. Burgess, D.S. Johnson, D.H. Johnson, S. Bucholtz, S. Hyberg, and S. Howlin. 2008. "Estimating the Response of Ring Necked Pheasants to the Conservation Reserve Program." The Auk 125(2): 434-444.

Rashford, B.S., J.A. Walker, and C.T. Bastian. 2010. "Economics of Grassland Conversion to Cropland in the Prairie Pothole Region." Conservation Biology 25(2): 276-284.

Reynolds, R.E., C.R. Loesch, B. Wangler, and T.L. Shaffer. 2007. Waterfowl Response to the Conservation Reserve Program and Swampbuster Provision in the Prairie Pothole Region, 1992-2004. Washington DC: US Fish and Wildlife Service / US Geological Survey.

Roberts, M.J., N. Key, and E.J. O’Donoghue. 2006. “Estimating the Extent of Moral Hazard in Crop Insurance Using Administrative Data." Review of Agricultural Economics 28(3): 381-90.

Roberts, M.J., and W. Schlenker. 2013. "Identifying Supply and Demand Elasticities of Agricultural Commodities: Implications for the US Ethanol Mandate." American Economic Review 103(6): 2265-2295.

Schoengold, K., Y. Ding, and R. Headlee. 2014. "The Impact of Ad Hoc Disaster and Crop Insurance Programs on the use of Risk-Reducing Conservation Tillage Practices." American Journal of Agricultural Economics 97(3): 897-919.

Secchi, S., P.W. Gassman, J.R. Williams, and B.A. Babcock. 2009. "Corn-Based Ethanol Production and Environmental Quality: A Case of Iowa and the Conservation Reserve Program." Environmental Management 44(4): 732-744. 
Sullivan, P., D. Hellerstein, L. Hansen, R. Johansson, S. Koenig, R.N. Lubowski, ... S. Bucholz, (n.d.). 2004. "The Conservation Reserve Program: Economic Implications for Rural America." SSRN Electronic Journal SSRN Journal.

USDA Economic Research Service, "Conservation-Compatible Practices and Programs: Who Participates?," D. Lambert, P. Sullivan, R. Claassen, and L. Foreman. Economic Research Report No. 14, Washington, DC: U.S. Department of Agriculture, 2006.

USDA Economic Research Service, "Conservation Compliance: How Farmer Incentives Are Changing in the Crop Insurance Era," R. Claassen, M. Bowman, V. Breneman, T. Wade, R. Williams, J. Fooks, L. Hansen, R. Iovanna, and C. Loesch. Economic Research Report No. 234, Washington, DC: U.S. Department of Agriculture, 2017.

USDA Economic Research Service, "Conservation Reserve Program Acreage to Decline; Will Benefits Also Fall?," R. Claassen and D. Hellerstein. Amber Waves, Washington, DC: U.S. Department of Agriculture, 2008.

USDA Economic Research Service, "Environmental Effects of Agricultural Land-Use Changes: The Role of Economics and Policy," R.N. Lubowski, S. Bucholtz, R. Claassen, M.J. Roberts, J. C. Cooper, A. Gueorguieva, and R. Johansson. Economic Research Report No. 25, Washington, DC: U.S. Department of Agriculture, 2006.

USDA Economic Research Service, "Major Uses of Land in the United States, 2012," D.P. Bigelow and A. Borchers. Economic Information Bulletin No. 178, Washington, DC: U.S. Department of Agriculture, 2017.

USDA Farm Service Agency. Conservation Reserve Program Statistics. Washington, DC: U.S. Department of Agriculture, 2018.

USDA Risk Management Agency. Summary of Business Report. Washington, DC: U.S. Department of Agriculture, 2016.

U.S. Geological Survey. "Ecosystem Services Derived from Wetland Conservation Practices in the United States Prairie Pothole Region with an Emphasis on the U.S. Department of Agriculture Conservation Reserve and Wetlands Reserve Programs," R.A.Gleason, M.K. Laubhan, B.A. Tangen, and K.E. Kermes. US Geological Survey Professional Paper 1745, Washington, DC: U.S. Department of the Interior, 2008.

U.S. National Commission on Terrorist Attacks upon the United States, 9/11 Commission Report: The Official Report of the 9/11 Commission and Related Publications, Thomas H. Kean and Lee Hamilton, Y 3.2:T 27/2/FINAL, Washington, DC: GPO, 2004.

Wachenheim, C.J., W.C. Lesch, and N. Dhingra. 2014. The Conservation Reserve Program: A Literature Review. Technical Report, North Dakota State University, Department of Agribusiness and Applied Economics.

Walters, C., C.R. Shumway, H. Chouinard, and P. Wandschneider. 2012. “Crop Insurance, Land Allocation, and the Environment." Journal of Agricultural and Resource Economics 37(2): 301-320.

Wu, J. 1999. “Crop Insurance, Acreage Decisions, and Nonpoint-Source Pollution." American Journal of Agricultural Economics 81(2): 305-320.

2000. "Slippage Effects of the Conservation Reserve Program." American Journal of Agricultural Economics 82(4): 979-992.

Wu, J., and R.M. Adams. 2001. "Production Risk, Acreage Decisions and Implications for Revenue Insurance Programs." Canadian Journal of Agricultural Economics 49: 19-35.

Wu, J., and B. Weber. 2012. Implications of a Reduced Conservation Reserve Program. The Conservation Crossroads in Agriculture. The Council on Food, Agricultural, and Resource Economics.

Young, C.E., M.L. Vandeveer, and R.D. Schnepf. 2001. "Production and Price Impacts of U.S. Crop Insurance Programs." American Journal of Agricultural Economics 83(5): 1196-1203.

Yu, J., A. Smith, and D.A. Sumner. 2018. "Effects of Crop Insurance Premium Subsidies on Crop Acreage." American Journal of Agricultural Economics 100(1): 91-114. 